Research Paper

\title{
Comparison of Sufentanil- and Fentanyl-based Intravenous Patient-controlled Analgesia on Postoperative Nausea and Vomiting after Laparoscopic Nephrectomy: A Prospective, Double-blind, Randomized-controlled Trial
}

\author{
Hye-Mi Lee, Hae Keum Kil, Bon Nyeo Koo, Min Sup Song, Jin Ha Park ${ }^{\bowtie}$ \\ Department of Anesthesiology and Pain Medicine, and Anesthesia and Pain Research Institute, Yonsei University College of Medicine, Seoul, Republic of Korea. \\ $\triangle$ Corresponding author: Jin Ha Park, MD, PhD., Department of Anesthesiology and Pain Medicine and Anesthesia and Pain Research Institute, Yonsei \\ University College of Medicine, 50 Yonsei-ro, Seodaemun-gu, Seoul, 03722, Republic of Korea. Phone: 82-2-2228-2420; Fax: 82-2-312-7185; E-mail: \\ realsummer@yuhs.ac
}

(c) The author(s). This is an open access article distributed under the terms of the Creative Commons Attribution License (https://creativecommons.org/licenses/by/4.0/). See http://ivyspring.com/terms for full terms and conditions.

Received: 2019.08.16; Accepted: 2019.12.12; Published: 2020.01.14

\begin{abstract}
Background: The incidence of postoperative nausea and vomiting (PONV) remains high. The effects of sufentanil for PONV is not firmly confirmed. The aim of this study was to compare the effect of sufentanil- and fentanyl-based intravenous patient-controlled analgesia (IV-PCA) on the incidence of PONV after laparoscopic nephrectomy.

Methods: Eighty-six patients were randomly allocated to receive either the sufentanil $(n=43)$ or fentanyl ( $\mathrm{n}=43$ ). IV-PCA was prepared using either sufentanil $3 \mu \mathrm{g} / \mathrm{kg}$ or fentanyl $20 \mu \mathrm{g} / \mathrm{kg}$, ramosetron $0.3 \mathrm{mg}$, and ketorolac $120 \mathrm{mg}$. The primary outcome of was the incidence of PONV during $24 \mathrm{~h}$ after post anesthesia care unit (PACU) discharge. The secondary outcomes were the modified Rhodes index and patient satisfaction scores at $24 \mathrm{~h}$ after PACU discharge, need for rescue antiemetics, pain score, need for additional analgesics, and cumulative consumption of IV-PCA

Results: The incidence of PONV was comparable between the sufentanil and fentanyl groups $(64.3 \%$ vs. $65 \%, p=0.946$; respectively). The number of patients who required antiemetics $(p=$ $0.946)$ and the modified Rhodes index at $24 \mathrm{~h}$ after post-anesthesia care unit discharge $(p=0.668)$ were also comparable in both groups. No significant differences were found in the secondary outcomes, including the analgesic profiles and adverse events between the groups.

Conclusions: In conclusion, sufentanil- and fentanyl-based IV-PCA showed similar incidence of PONV with comparable analgesic effects after laparoscopic nephrectomy. Based on these results, we suggest that sufentanil and fentanyl may provide comparable effects for IV-PCA after laparoscopic nephrectomy.
\end{abstract}

Key words: fentanyl; intravenous patient-controlled analgesia; laparoscopic nephrectomy; postoperative nausea and vomiting; sufentanil

\section{Introduction}

Intravenous patient-controlled analgesia (IV-PCA), which is based on strong opioids, is widely used for postoperative pain relief. Among these opioids, the three synthetic ones, alfentanil, fentanyl and sufentanil are the most common in anesthetic practice. Opioids act mainly on mu-receptors and exhibit powerful analgesic effects; however, inevitable side effects such as postoperative nausea and 
vomiting (PONV) are frequently encountered. Opioids are indeed a double-edged sword for PONV, because insufficient pain control after surgery itself is a risk factor for PONV while the incidence of PONV is dose-dependent with opioids.[1,2]

PONV decreases patient satisfaction, and may adversely affect prognosis by increasing wound dehiscence and dehydration, which may result in aspiration pneumonia and delayed recovery.[3,4] The pathogenesis of PONV involves multiple pathways, including pain, anxiety, surgery-related factors and stimulation of the chemoreceptor trigger zone (CTZ) by anesthetics or opioids via neurotransmitters (e.g., dopamine, acetylcholine, histamine and serotonin). These factors often influence and/or overlap with each other, leading to PONV.[1,5] To date, no single strategy has conclusively demonstrated an ability to prevent PONV.

Although laparoscopic surgery is considered advantageous due to the lower risk of postoperative pain and bleeding than open surgery, but it is classified as high-risk surgery for PONV due to the use of carbon dioxide $\left(\mathrm{CO}_{2}\right)$ for pneumoperitoneum. $[1,6]$ In this subset of patients, the incidence of PONV has been reported to be as high as $50-75 \% .[1,6]$ Thus, these high-risk patients might be targeted for PONV prevention by eliminating correctable risk factors, such as opioid dose reduction or proper pain management. [1,4]

Fentanyl is often used to control postoperative pain because of its relatively fast effect and short duration, whereas its incidence of PONV is relatively high. $[7,8]$ Sufentanil has a faster onset of action due to its higher affinity for mu-opioid receptors, lipophilic properties, and easier passage through the blood-brain barrier; therefore, it exhibits the most potent analgesic effect among clinically applied opioids.[9-12] Additionally, although previous studies have yielded conflicting results, it is known that sufentanil is associated with a lower incidence of PONV than fentanyl due to its structural properties.[13,14] However, limited data are available comparing these two drugs on the incidence and severity of PONV in patients undergoing laparoscopic nephrectomy who are at high risk for PONV. Therefore, we designed this double-blind randomized controlled study to compare the fentanyl and sufentanil-based IV-PCA on the incidence and severity of PONV in patients undergoing laparoscopic nephrectomy.

\section{Methods}

This study was conducted at Severance Hospital, Yonsei University Health System, Seoul, Korea, approved by our institutional review board (IRB number, 4-2017-0201), and registered at http://www.ClinicalTrials.gov (NCT03171610). Written informed consent was obtained from each patient before study enrollment.

\section{Patients}

Eighty-six patients, aged 20 to 70 years, with an American Society of Anesthesiologists (ASA) physical status I-III scheduled for elective laparoscopic or robot-assisted laparoscopic nephrectomy, and who required IV-PCA for postoperative pain control were enrolled. Patients were excluded if they met at least one of the following criteria: (1) long-term use of opioids, pain killers or tranquilizers; (2) a history of diabetic neuropathy; (3) a prolonged prothrombin time or an activated partial thromboplastin time; (4) cognitive function impairment; (5) obesity (body mass index $\geq 30 \mathrm{~kg} / \mathrm{m}^{2}$ ); (6) conversion from a laparoscopic to open surgery; or (7) reoperation within $24 \mathrm{~h}$.

Patients were randomly assigned to either sufentanil ( $\mathrm{n}=43$ ) or fentanyl group $(\mathrm{n}=43)$. Randomization was performed by computer-generated randomized numbers. For each patient, group assignments were kept in a sequentially numbered sealed, opaque envelope. An investigator who was not involved with outcome measurement and patient care opened the envelope on the day of surgery and prepared the IV-PCA according to the group assignment.

\section{Anesthetic management and Intervention}

Premedication was not administered. After applying standard monitoring devices, general anesthesia was induced with propofol $2 \mathrm{mg} / \mathrm{kg}$, remifentanil $1 \mu \mathrm{g} / \mathrm{kg}$, and rocuronium $0.8 \mathrm{mg} / \mathrm{kg}$. Anesthesia was maintained with sevoflurane or desflurane, with $50 \%$ oxygen in air, and remifentanil 0.1 to $0.2 \mu \mathrm{g} / \mathrm{kg} / \mathrm{min}$. The depth of anesthesia was controlled using a bispectral index (BIS) between 45 and 50. Propacetamol $15 \mathrm{mg} / \mathrm{kg}$ in total of $100 \mathrm{ml}$ of $0.9 \%$ normal saline was administered 20 min before the end of surgery, and fentanyl $1 \mu \mathrm{g} / \mathrm{kg}$ was injected $10 \mathrm{~min}$ before the end of surgery for postoperative pain prophylaxis. Ramosetron $0.3 \mathrm{mg}$ was administered at the end of surgery for nausea prophylaxis, followed by continuous infusion of IV-PCA.

IV-PCA was prepared using either sufentanil 3 $\mu \mathrm{g} / \mathrm{kg}$ or fentanyl $20 \mu \mathrm{g} / \mathrm{kg}$, ramosetron $0.3 \mathrm{mg}$, and ketorolac $120 \mathrm{mg}$ in $0.9 \%$ normal saline with a total volume of $100 \mathrm{ml}$ according to the group assignment. We administered fentanyl and sufentanil with a potency ratio of 1:7, based on results from a previous study.[14] The PCA device (Ambix anapa, Ewha Fresenius Kabi Inc., Gyeonggi-do, Korea) was 
programmed to deliver $2 \mathrm{~mL} / \mathrm{h}$ as the background infusion with a $0.5 \mathrm{ml}$ bolus at a 15-min lockout period.

\section{Assessments}

After surgery, patients were asked to report their nausea and vomiting upon arrival at the post-anesthesia care unit (PACU); 30 min after arrival at PACU; 1, 6, and $24 \mathrm{~h}$ after discharge from the PACU on a binary scale (yes or no). The severity of pain at rest and coughing was also assessed at the same interval using a verbal numerical rating scale (VNRS), where 0 means no pain and 10 is the worst imaginable. Intravenous metoclopramide $10 \mathrm{mg}$ was given as a rescue antiemetic at the patients' request. If severe nausea persisted after two consecutive rescue antiemetics, PCA was stopped for $2 \mathrm{~h}$ and restarted later when the symptoms subsided. Patients were allowed to receive intravenous pethidine $25 \mathrm{mg}$ when they complained of pain $>4$ on VNRS. The Ramsay sedation score and cumulative consumption of IV-PCA were recorded at the same interval to evaluate postoperative sedation due to opioid use. The modified Rhodes index score [15] was assessed to evaluate the severity of PONV at $24 \mathrm{~h}$ after PACU discharge. Patients were asked about their satisfaction with IV-PCA for the previous 24 hours, using a scale with 0 meaning not satisfied to 10 meaning to very satisfied. Any adverse events, such as pruritis and dizziness, were evaluated. Patients were assessed by a trained nurse who was blinded to the group assignment.

The primary outcome of this study was the incidence of PONV $24 \mathrm{~h}$ after PACU discharge. The secondary outcomes were the modified Rhodes index and patient satisfaction scores at $24 \mathrm{~h}$ after PACU discharge, pain score, the need for rescue antiemetics or additional analgesics, and cumulative consumption of IV-PCA. The time to first flatus was also assessed.

\section{Statistical analysis}

Sample size was calculated based on the previous studies that addressed the incidence of PONV in patients using fentanyl- or sufentanil-based IV-PCA for postoperative pain relief after various laparoscopic surgeries.[16-23] The average incidence of PONV during $24 \mathrm{~h}$ were $39 \%$ and $17 \%$ during in the fentanyl and sufentanil groups, respectively. Based on these findings, we assumed a $20 \%$ difference in the incidence of PONV between the two groups. Therefore, 39 patients were required in each group to obtain a power of $80 \%$ with an alpha of 0.05 . Considering a $10 \%$ dropout rate, we decided to enroll 43 patients in each group.
Statistical analysis was performed using SPSS 25 (SPSSFW, SPSS, IBM, Armonk, NY, USA). Continuous variables were expressed as mean \pm standard deviation (SD) or median [interquartile range] and were compared using Student's $t$ test or the Mann-Whitney $U$ test, as appropriate. Dichotomous variables were expressed as the number of patients (percentage) and were compared using Chi-square and or Fisher's exact test, as appropriate. For secondary analysis, Bonferroni correction was performed to compare inter-group differences of five time-points. $\mathrm{P}$ values of $<0.05$ were considered statistically significant.

\section{Results}

Between June 2017 and January 2018, a total of 86 patients were enrolled. One patient in the sufentanil group and two patients in the fentanyl group were excluded because surgery was converted to open surgery. One patient in the fentanyl group was excluded after the reoperation within $24 \mathrm{~h}$ due to postoperative bleeding (Figure 1).

Patients' demographic data were similar between the groups (Table 1). PONV occurred in 27 $(64.3 \%)$ and $26(65 \%)$ patients in the sufentanil and the fentanyl groups, respectively $(p=0.946)$ (Table 2$)$. The number of patients who required antiemetics and the modified Rhodes index at $24 \mathrm{~h}$ after PACU discharge were comparable between the groups (Table 2).

Table 1. Demographic data

\begin{tabular}{llll}
\hline & sufentanil group $(\mathrm{n}=$ & $\begin{array}{l}\text { fentanyl group }(\mathrm{n}= \\
40)\end{array}$ & P value \\
& $42)$ & $49 \pm 12$ & 0.291 \\
\hline Age $(\mathrm{yr})$ & $52 \pm 9$ & $165 \pm 10$ & 0.412 \\
Height $(\mathrm{cm})$ & $168 \pm 8$ & $68 \pm 11$ & 0.812 \\
Weight $(\mathrm{kg})$ & $67 \pm 11$ & $17(42.5 \%)$ & 0.651 \\
Female & $15(35.7 \%)$ & $2.5[2-3]$ & 0.959 \\
Apfel score & $2.5[2-3]$ & $12 / 28$ & $>0.999$ \\
Laparoscopic/Robotic & $12 / 30$ & & \\
surgery & & $23 / 15 / 2$ & 0.809 \\
ASA I/II/III & $21 / 19 / 2$ & $11(27.5 \%)$ & $>0.999$ \\
Hypertension & $12(28.6 \%)$ & $4(10 \%)$ & 0.709 \\
Diabetes & $3(7.1 \%)$ & $195[164-224]$ & 0.168 \\
Anesthesia time $(\mathrm{min})$ & $213[189-241]$ &
\end{tabular}

Data are presented as mean \pm standard deviation or median (interquartile range) and numbers (\%).

ASA, American Society of Anesthesiologists.

No differences were observed in the postoperative analgesic profiles, including pain scores at rest and during coughing, the number of patients who required analgesics, cumulative consumed volume of IV-PCA, the number of patients who clamped the IV-PCA, and the patient satisfaction score between the groups (Table 3 ). There were no significant differences in postoperative adverse events and Ramsay sedation score (Table 4).

The number of patients who required antiemetics ( 26 vs. $3, \mathrm{p}=0.001)$, stopped IV-PCA (36 vs. 
$7, \mathrm{p}<0.001)$ and reported dizziness (37 vs. 10, $\mathrm{p}=0.003$ ) were higher in patients with PONV than in those without PONV, respectively. Postoperative analgesic profiles, time to flatus, and patient satisfaction score were not significantly different between patients with PONV and without PONV (data not shown).

Table 2. The incidence of postoperative nausea and vomiting, modified Rhodes index, and use of rescue antiemetics.

\begin{tabular}{|c|c|c|c|}
\hline & $\begin{array}{l}\text { sufentanil group (n } \\
=42 \text { ) }\end{array}$ & $\begin{array}{l}\text { fentanyl group }(\mathrm{n}= \\
40)\end{array}$ & P value \\
\hline \multicolumn{4}{|l|}{$\begin{array}{l}\text { Incidence of } \\
\text { nausea/vomiting }\end{array}$} \\
\hline Overall & $27(64.3 \%) / 4(9.5 \%)$ & $26(65 \%) / 4(10 \%)$ & $\begin{array}{l}0.946 / \\
>0.999\end{array}$ \\
\hline PACU arrival & $5(11.9 \%) / 0(0 \%)$ & $4(10 \%) / 0(0 \%)$ & $>0.999 /-$ \\
\hline $30 \mathrm{~min}$ at $\mathrm{PACU}$ & $2(4.8 \%) / 0(0 \%)$ & $4(7.5 \%) / 0(0 \%)$ & $0.672 /-$ \\
\hline $1 \mathrm{~h}$ after PACU discharge & $9(21.4 \%) / 0(0 \%)$ & $11(27.5 \%) / 0(0 \%)$ & $0.522 /-$ \\
\hline $6 \mathrm{~h}$ after PACU discharge & $11(26.2 \%) / 3(7.1 \%)$ & $12(30.0 \%) / 2(5 \%)$ & $\begin{array}{l}0.701 / \\
>0.999\end{array}$ \\
\hline $\begin{array}{l}24 \mathrm{~h} \text { after PACU } \\
\text { discharge }\end{array}$ & $23(54.8 \%) / 4(9.5 \%)$ & $17(42.5 \%) / 4(10 \%)$ & $\begin{array}{l}0.267 / \\
>0.999\end{array}$ \\
\hline \multicolumn{4}{|c|}{ Number of patients who required antiemetics } \\
\hline Overall & $15(35.7 \%)$ & $14(35 \%)$ & 0.946 \\
\hline PACU arrival & $4(9.5 \%)$ & $3(7.5 \%)$ & $>0.999$ \\
\hline $30 \mathrm{~min}$ at PACU & $2(4.8 \%)$ & $0(0 \%)$ & 0.494 \\
\hline $1 \mathrm{~h}$ after PACU discharge & $5(11.9 \%)$ & $4(10 \%)$ & $>0.999$ \\
\hline $6 \mathrm{~h}$ after PACU discharge & $6(14.3 \%)$ & $7(17.5 \%)$ & 0.690 \\
\hline $\begin{array}{l}24 \mathrm{~h} \text { after PACU } \\
\text { discharge }\end{array}$ & $7(16.7 \%)$ & $6(15 \%)$ & 0.836 \\
\hline Modified Rhodes index & $4[0-9]$ & $3[0-8]$ & 0.668 \\
\hline
\end{tabular}

Data are presented as numbers (\%)

PACU, postoperative anesthesia care unit.
Table 3. Postoperative analgesic profiles

\begin{tabular}{|c|c|c|c|}
\hline & $\begin{array}{l}\text { sufentanil group } \\
(\mathrm{n}=42)\end{array}$ & $\begin{array}{l}\text { fentanyl group } \\
(\mathrm{n}=40)\end{array}$ & $P$ value \\
\hline \multicolumn{4}{|l|}{$\begin{array}{l}\text { VNRS of pain (at rest/ during } \\
\text { coughing) }\end{array}$} \\
\hline PACU arrival & $6[3-7] / 7[5-8]$ & $5[4-7] / 6[5-8]$ & $0.428 / 0.594$ \\
\hline $30 \mathrm{~min}$ at PACU & $5[3-5] / 6[4-7]$ & $4[4-5] / 5[4-6]$ & $0.569 / 0.507$ \\
\hline $1 \mathrm{~h}$ after PACU discharge & $5[4-7] / 7[5-8]$ & $5[2-6] / 6[5-8]$ & $0.428 / 0.403$ \\
\hline $6 \mathrm{~h}$ after PACU discharge & $2[0-4] / 4[2-6]$ & $3[1-4] / 4[3-8]$ & $0.475 / 0.858$ \\
\hline $24 \mathrm{~h}$ after PACU discharge & $1[0-2] / 4[2-4]$ & $1[0-3] / 4[2-5]$ & $0.614 / 0.839$ \\
\hline \multicolumn{4}{|c|}{ Number of patients who required analgesics } \\
\hline Overall & $30(71.4 \%)$ & $28(70 \%)$ & $>0.999$ \\
\hline PACU arrival & $24(57.1 \%)$ & $17(42.5 \%)$ & 0.269 \\
\hline $30 \mathrm{~min}$ at $\mathrm{PACU}$ & $6(14.3 \%)$ & $5(12.5 \%)$ & $>0.999$ \\
\hline $1 \mathrm{~h}$ after PACU discharge & $13(31 \%)$ & $10(25 \%)$ & 0.627 \\
\hline $6 \mathrm{~h}$ after PACU discharge & $5(11.9 \%)$ & $7(17.5 \%)$ & 0.543 \\
\hline $24 \mathrm{~h}$ after PACU discharge & $5(11.9 \%)$ & $7(17.5 \%)$ & 0.543 \\
\hline \multicolumn{4}{|c|}{ Cumulative volume of IV-PCA consumed $(\mathrm{mL})$} \\
\hline PACU arrival & $4[2-5]$ & $5[3-6]$ & 0.891 \\
\hline $30 \mathrm{~min}$ at $\mathrm{PACU}$ & $5[4-8]$ & $6[4-8]$ & 0.799 \\
\hline $1 \mathrm{~h}$ after PACU discharge & $10[6-15]$ & $9[7-12]$ & 0.962 \\
\hline $6 \mathrm{~h}$ after PACU discharge & $32[21-42]$ & $35[20-40]$ & 0.919 \\
\hline $24 \mathrm{~h}$ after PACU discharge & $56[38-65]$ & $50[40-60]$ & 0.688 \\
\hline $\begin{array}{l}\text { Number of patients who } \\
\text { clamped the IV-PCA }\end{array}$ & $22(52.4 \%)$ & $21(52.5 \%)$ & $>0.999$ \\
\hline Patient satisfaction score & $4[3-4]$ & $4[3-5]$ & 0.394 \\
\hline
\end{tabular}

Data are presented as median (interquartile range) and numbers (\%).

IV-PCA, intravenous patient-controlled analgesia; PACU, post-anesthesia care unit; VNRS, verbal numerical rating scale.

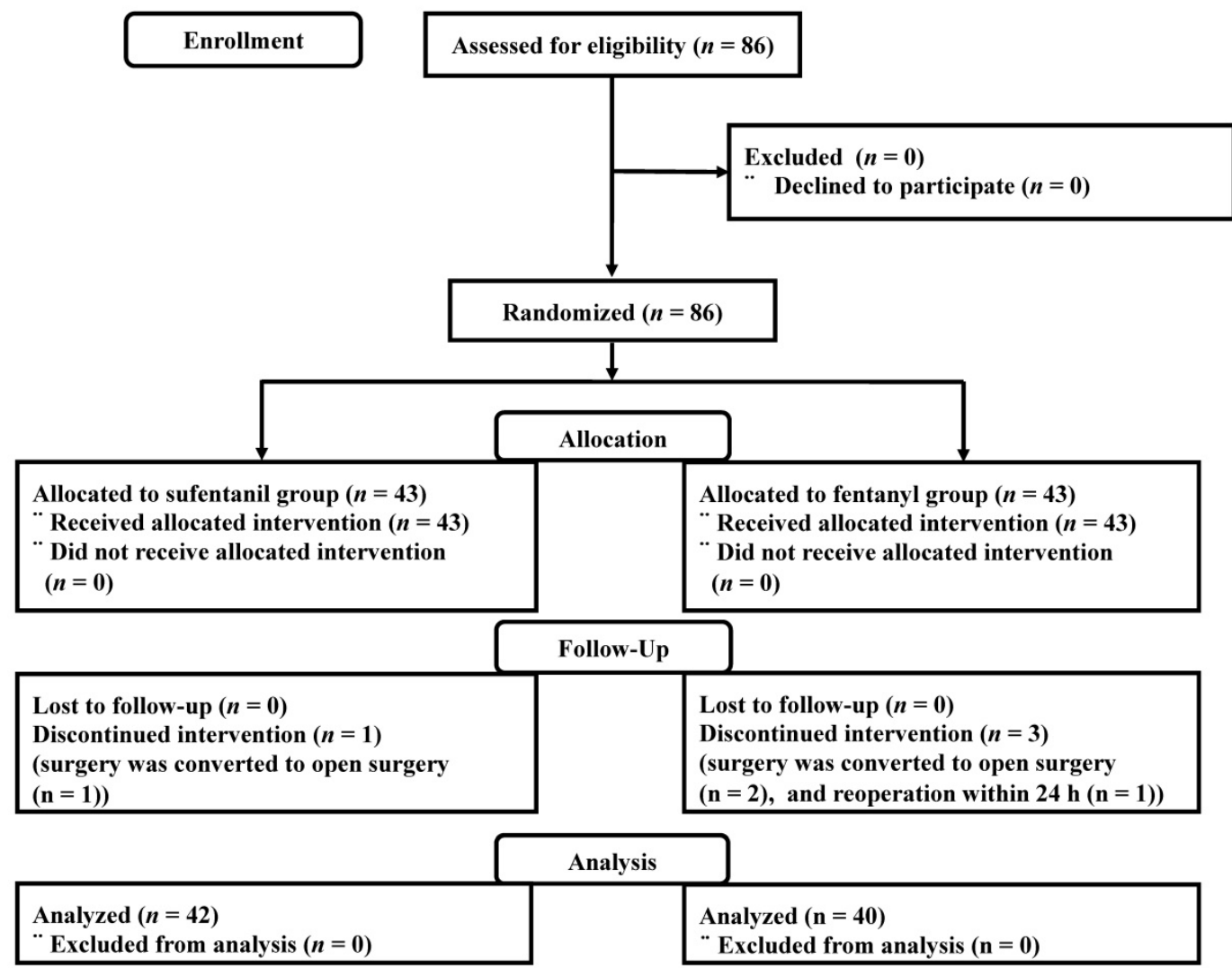

Figure 1. Consort flow diagram. 
Table 4. Postoperative adverse events and Ramsay sedation score

\begin{tabular}{|c|c|c|c|}
\hline & $\begin{array}{l}\text { sufentanil group }(n= \\
42)\end{array}$ & $\begin{array}{l}\text { fentanyl group }(\mathrm{n}= \\
40)\end{array}$ & Pvalue \\
\hline Time to flatus (h) & $18[12-27]$ & $19[14-23]$ & 0.950 \\
\hline Dizziness & $25(59.5 \%)$ & $22(55 \%)$ & 0.824 \\
\hline Pruritis & $0(0 \%)$ & $1(2.5 \%)$ & 0.488 \\
\hline \multicolumn{4}{|l|}{ Ramsay sedation score } \\
\hline PACU arrival & 2 [1-2] & $2[2-2]$ & 0.058 \\
\hline $30 \mathrm{~min}$ at PACU & $2[1-2]$ & $2[2-2]$ & $>0.999$ \\
\hline $1 \mathrm{~h}$ after PACU discharge & $2[1-2]$ & $2[2-2]$ & 0.503 \\
\hline $6 \mathrm{~h}$ after PACU discharge & $2[1-2]$ & $2[2-2]$ & $>0.999$ \\
\hline $\begin{array}{l}24 \mathrm{~h} \text { after PACU } \\
\text { discharge }\end{array}$ & $2[1-2]$ & $2[2-2]$ & $>0.999$ \\
\hline
\end{tabular}

\section{Discussion}

This prospective, double-blind, randomized controlled trial in patients undergoing laparoscopic nephrectomy showed no difference in the incidence of PONV between sufentanil-based and fentanyl-based IV-PCA. Additionally, the intensity of PONV and the postoperative pain profiles were comparable between the two treatment groups.

Despite many dedicated efforts to reduce the incidence of PONV, it still remains "the big little problem", as Kapur described. [24] The mechanisms of PONV are multifactorial, and Apfel's risk factors for PONV include female gender, non-smoker, postoperative opioid use, and a history of PONV or motion sickness.[4] Among these, postoperative opioid use is the only correctable factor; although, the use of opioids is inevitable after major surgery. Therefore, current strategies to manage and prevent PONV focus on the avoidance of higher doses of opioids and choosing an appropriate type of opioid as well as prophylactic administration of antiemetic drugs.[8,25,26]

Although there is still debate regarding whether the type of surgery contributes to the development of PONV, laparoscopic surgery has a potential to increase the incidence of PONV compared with open surgery due to the use of $\mathrm{CO}_{2}$ pneumoperitoneum, which results in peritoneal distension and visceral irritation.[27] In a previous study, Yamanaga et al. reported an incidence of PONV higher than $60 \%$ in patients undergoing laparoscopic donor nephrectomy.[28] Therefore, an opioid-based PCA regimen with a lower risk of PONV is particularly important among high-risk laparoscopic surgery patients.

In this present study of patients undergoing laparoscopic nephrectomy, the incidence of PONV at $24 \mathrm{~h}$ after PACU discharge was $64.3 \%$ in the sufentanil group and $65 \%$ in the fentanyl group without significant difference. A possible explanation for this high incidence of PONV is that more than $50 \%$ of patients had Apfel scores of 3 or 4 in both groups. In a previous study comparing sufentanil- and fentanyl-based IV-PCA after lumbar fusion, the incidences of PONV was $4.76 \%$ and $28.5 \%$ in the sufentanil and fentanyl groups, respectively, even though they used higher doses of sufentanil $(4 \mu \mathrm{g} / \mathrm{kg})$ and fentanyl $(24 \mu \mathrm{g} / \mathrm{kg})$ than those in this study.[14] Considering that Kim et al and Choi et al reported approximately $70 \%$ incidence of PONV in highly susceptible patients undergoing lumbar surgery, $[29,30]$ while Park et al reported approximately $30 \%$ incidence with a similar dose of fentanyl-based IV-PCA in patients at moderate risk undergoing lumbar surgery,[31] the PONV risk itself, in other words, individual patients' susceptibility may be important in the development of PONV. [32] Furthermore, a lower incidence of PONV in the sufentanil group than that in the fentanyl group in the Kim et al's study [14] was possibly due to the lower proportion of females, consequently leading to a lower risk of PONV.

Numerous previous studies comparing sufentanil and fentanyl have focused on intrathecal injection, epidural PCA, and intraoperative infusion. $[8,33,34]$ Few studies have compared the effect of sufentanil- and fentanyl-based IV-PCA on the relative emetic potencies. Opioid-induced nausea and vomiting occur via stimulation of the CTZ or the vestibular apparatus, mediated by activation of the opioid mu receptor.[35,36] Notably, the CTZ is located outside the blood-brain barrier and contains a high concentration of opioid receptors. Therefore, the CTZ is susceptible to opioid stimulation.[36] Sufentanil has an 8-10 times higher lipid solubility than fentanyl, with a higher affinity for the mu-opioid receptor, and 5-10 times more potency than fentanyl; thus, smaller doses are required to achieve an analgesic effect. [11] Because the opioid-induced PONV risk increases in a dose-dependent manner,[2] it has been suggested that sufentanil-based IV-PCA provide a powerful analgesic effect with a lower incidence of PONV than fentanyl-based IV-PCA.

Contrary to our expectation, the incidence of PONV was similar between the groups. The intensity of PONV reported by the modified Rhodes index at 24 $\mathrm{h}$ after surgery, the number of patients who required rescue antiemetics was also comparable throughout the study period. Because pain increases the incidence of PONV, we compared pain profiles, and there were no differences in pain profiles between the groups. The incidences of other opioid-related side effects, including dizziness and pruritis, were similar, and no patients reported excessive sedation in each group. Based on the results that there were no differences in 
all comparative values between the two groups, we suggest that the sufentanil and fentanyl dose ratio used in this study (1: 7) seems to be clinically equivalent.

It is noteworthy that the PCA satisfaction score and pain profiles were similar between patients with and without PONV; although, more patients with PONV stopped IV-PCA and required antiemetics. Therefore, this regimen of IV-PCA seems to be adequate for pain control in laparoscopic nephrectomy. Because ketorolac is also added to lower the opioid dose, other methods, such as adding two or more antiemetics with different mechanisms of action, should be considered to lower the incidence of PONV in moderate- to high-risk patients.[37] Alternatively, considerably lower opioid doses may be needed for pain relief based on the fact that mutant variant of mu-opioid receptor genes is more sensitive and prevalent in Asian populations.[38] However, this is beyond the scope of this study and will not discussed further here.

This study has limitations. The severity of PONV, which was evaluated by the modified Rhodes index, was assessed only at $24 \mathrm{~h}$ after PACU discharge. Although the incidence of PONV did not differ at each time point, there is a possibility that the severity of PONV might be different between the groups at different time point. However, we estimated the severity of PONV through the incidence of PONV and the number of patients who required antiemetics at each time point.

In conclusion, sufentanil-based and fentanyl-based IV-PCA showed a similar incidence of PONV with comparable analgesic effects after laparoscopic nephrectomy. Based on these results, we suggest that sufentanil and fentanyl may provide comparable effects for PCA after laparoscopic nephrectomy.

\section{Abbreviations}

ASA: american society of anesthesiologists; BIS: bispectral index; $\mathrm{CO}_{2}$ : carbon dioxide; CTZ: chemoreceptor trigger zone; IV-PCA: intravenous patient-controlled analgesia; PACU: post-anesthesia care unit; PONV: postoperative nausea and vomiting; VNRS: verbal numerical rating scale.

\section{Acknowledgments}

We wish to thank Won-Hee Baek and Mirr Moon for participating in this study.

\section{Funding}

This work was supported in part by a research grant from the BC World Pharm. The opinions expressed in this paper are those of the authors and do not necessarily represent those of BC World Pharm.

\section{Competing Interests}

The authors have declared that no competing interest exists.

\section{References}

1. Gan TJ. Risk factors for postoperative nausea and vomiting. Anesth Analg 2006; 102(6):1884-98

2. Roberts GW, Bekker TB, Carlsen $\mathrm{HH}$, Moffatt $\mathrm{CH}$, Slattery PJ, McClure AF Postoperative nausea and vomiting are strongly influenced by postoperative opioid use in a dose-related manner. Anesthesia \& Analgesia 2005; 101(5):1343-8.

3. Cohen MM, Duncan PG, DeBoer DP, Tweed WA. The postoperative interview: assessing risk factors for nausea and vomiting. Anesth Analg 1994; 78(1):7-16.

4. Apfel CC, Korttila K, Abdalla M, Kerger H, Turan A, Vedder I, et al. A factorial trial of six interventions for the prevention of postoperative nausea and vomiting. N Engl J Med 2004; 350(24):2441-51.

5. Watcha MF, White PF. Postoperative nausea and vomiting. Its etiology, treatment, and prevention. Anesthesiology 1992; 77(1):162-84.

6. Karanicolas PJ, Smith SE, Kanbur B, Davies E, Guyatt GH. The impact of prophylactic dexamethasone on nausea and vomiting after laparoscopic cholecystectomy: a systematic review and meta-analysis. Ann Surg 2008; 248(5):751-62.

7. Patrick M, Eagar BM, Toft DF, Sebel PS. Alfentanil-supplemented anaesthesia for short procedures. A double-blind comparison with fentanyl. Br J Anaesth 1984; 56(8):861-6

8. Langevin S, Lessard MR, Trepanier CA, Baribault JP. Alfentanil causes less postoperative nausea and vomiting than equipotent doses of fentanyl or sufentanil in outpatients. Anesthesiology 1999; 91(6):1666-73.

9. Nie Y, Liu Y, Luo Q, Huang S. Effect of dexmedetomidine combined with sufentanil for post-caesarean section intravenous analgesia: a randomised, placebo-controlled study. Eur J Anaesthesiol 2014; 31(4):197-203.

10. Maciejewski D. Sufentanil in anaesthesiology and intensive therapy. Anaesthesiol Intensive Ther 2012; 44(1):35-41.

11. Leysen JE, Gommeren W, Niemegeers CJ. [3H]Sufentanil, a superior ligand for mu-opiate receptors: binding properties and regional distribution in rat brain and spinal cord. Eur J Pharmacol 1983; 87(2-3):209-25.

12. Rosow CE. Sufentanil citrate: a new opioid analgesic for use in anesthesia. Pharmacotherapy: The Journal of Human Pharmacology and Drug Therapy 1984; 4(1):11-8

13. Lin CS, Lu G, Ruan LY, Gu MN. [Patient-controlled intravenous analgesia with sufentanil and fentanyl after thoracotomy: a comparative study]. Nan Fang Yi Ke Da Xue Xue Bao 2006; 26(2):240-1, 4.

14. Kim DK, Yoon SH, Kim JY, Oh CH, Jung JK, Kim J. Comparison of the Effects of Sufentanil and Fentanyl Intravenous Patient Controlled Analgesia after Lumbar Fusion. J Korean Neurosurg Soc 2017; 60(1):54-9.

15. Rhodes VA, McDaniel RW. The Index of Nausea, Vomiting, and Retching: a new format of the Index of Nausea and Vomiting. Oncol Nurs Forum 1999; 26(5):889-94.

16. Kim S-H, Oh C-S, Lee SJ. Efficacy of palonosetron and ramosetron on postoperative nausea and vomiting related to intravenous patient-controlled analgesia with opioids after gynecological laparoscopic surgery (double-blinded prospective randomized controlled trial). J Anesth 2015; 29(4):585-92.

17. Oh CS, Jung E, Lee SJ, Kim SH. Effect of nefopam- versus fentanyl-based patient-controlled analgesia on postoperative nausea and vomiting in patients undergoing gynecological laparoscopic surgery: a prospective double-blind randomized controlled trial. Curr Med Res Opin 2015; 31(8):1599-607.

18. Wang $X$, Liu $W, X u ~ Z$, Wang $F$, Zhang $C$, Wang B, et al. Effect of Dexmedetomidine Alone for Intravenous Patient-Controlled Analgesia After Gynecological Laparoscopic Surgery: A Consort-Prospective, Randomized, Controlled Trial. Medicine (Baltimore) 2016; 95(19):e3639.

19. Wang N, Zhou H, Song X, Wang J. Comparison of oxycodone and sufentanil for patient-controlled intravenous analgesia after laparoscopic radical gastrectomy: A randomized double-blind clinical trial. Anesth Essays Res 2016; 10(3):557-60

20. Chen XH, Wang ZJ, Xiang QM, Zheng JW. [Effect of dexmedetomidine alone for postoperative analgesia after laparoscopic cholecystectomy]. Zhonghua Yi Xue Za Zhi 2017; 97(4):295-9.

21. Park JH, Lee C, Shin Y, An JH, Ban JS, Lee JH. Comparison of oxycodone and fentanyl for postoperative patient-controlled analgesia after laparoscopic gynecological surgery. Korean J Anesthesiol 2015; 68(2):153-8.

22. Zhang $\mathrm{XK}$, Chen $\mathrm{OH}$, Wang $\mathrm{WX}, \mathrm{Hu} \mathrm{O}$. Evaluation of dexmedetomidine in combination with sufentanil or butorphanol for postoperative analgesia in patients undergoing laparoscopic resection of gastrointestinal tumors: A quasi-experimental trial. Medicine (Baltimore) 2016; 95(50):e5604. 
23. Wang J, Ma H, Zhou H, Gao Y, Fu Y, Wang N. Effect of preoperative intravenous oxycodone administration on sufentanil consumption after retroperitoneal laparoscopic nephrectomy. Anaesthesiol Intensive Ther 2016; 48(5):300-4.

24. Kapur PA. The big "little problem". Anesth Analg 1991; 73(3):243-5.

25. Ziemann-Gimmel P, Goldfarb AA, Koppman J, Marema RT. Opioid-free total intravenous anaesthesia reduces postoperative nausea and vomiting in bariatric surgery beyond triple prophylaxis. Br J Anaesth 2014; 112(5):906-11.

26. Moon YE. Postoperative nausea and vomiting. Korean J Anesthesiol 2014; 67(3):164-70.

27. Apfel CC, Heidrich FM, Jukar-Rao S, Jalota L, Hornuss C, Whelan RP, et al. Evidence-based analysis of risk factors for postoperative nausea and vomiting. Br J Anaesth 2012; 109(5):742-53.

28. Yamanaga S, Posselt AM, Freise CE, Kobayashi T, Tavakol M, Kang SM. A Single Perioperative Injection of Dexamethasone Decreases Nausea, Vomiting, and Pain after Laparoscopic Donor Nephrectomy. J Transplant 2017; 2017:3518103.

29. Kim EJ, Shim JK, Soh S, Song JW, Lee SR, Kwak YL. Patient-controlled Analgesia With Propacetamol-Fentanyl Mixture for Prevention of Postoperative Nausea and Vomiting in High-risk Patients Undergoing Spine Surgery: A Randomized Controlled Trial. J Neurosurg Anesthesiol 2016; 28(4):316-22.

30. Choi YS, Shim JK, Yoon DH, Jeon DH, Lee JY, Kwak YL. Effect of ramosetron on patient-controlled analgesia related nausea and vomiting after spine surgery in highly susceptible patients: comparison with ondansetron. Spine (Phila Pa 1976) 2008; 33(17):E602-6.

31. Park JH, Shim JK, Song JW, Jang J, Kim JH, Kwak YL. A Randomized, Double-blind, Non-inferiority Trial of Magnesium Sulphate versus Dexamethasone for Prevention of Postoperative Sore Throat after Lumbar Spinal Surgery in the Prone Position. Int J Med Sci 2015; 12(10):797-804.

32. Janicki PK, Vealey R, Liu J, Escajeda J, Postula M, Welker K. Genome-wide association study using pooled DNA to identify candidate markers mediating susceptibility to postoperative nausea and vomiting. Anesthesiology 2011; 115(1):54-64.

33. Jeon HR, Chae WS, Lee SJ, Lee JH, Cho SH, Kim SH, et al. A comparison of sufentanil and fentanyl for patient-controlled epidural analgesia in arthroplasty. Korean J Anesthesiol 2011; 60(1):41-6.

34. Kim SY, Cho JE, Hong JY, Koo BN, Kim JM, Kil HK. Comparison of intrathecal fentanyl and sufentanil in low-dose dilute bupivacaine spinal anaesthesia for transurethral prostatectomy. Br J Anaesth 2009; 103(5):750-4.

35. Porreca F, Ossipov MH. Nausea and vomiting side effects with opioid analgesics during treatment of chronic pain: mechanisms, implications, and management options. Pain Med 2009; 10(4):654-62.

36. Silva AC, O'Ryan F, Poor DB. Postoperative nausea and vomiting (PONV) after orthognathic surgery: a retrospective study and literature review. J Oral Maxillofac Surg 2006; 64(9):1385-97.

37. Gan TJ, Diemunsch P, Habib AS, Kovac A, Kranke P, Meyer TA, et al. Consensus guidelines for the management of postoperative nausea and vomiting. Anesth Analg 2014; 118(1):85-113.

38. Landau R, Kern C, Columb MO, Smiley RM, Blouin JL. Genetic variability of the mu-opioid receptor influences intrathecal fentanyl analgesia requirements in laboring women. Pain 2008; 139(1):5-14. 